The Astrophysical Journal, Vol 156, June 1969

(C) 1969 The University of Chicago All rights reserved Printed in U S A

\title{
RESULTS OF FIVE NIGHTS OF CONTINUOUS MONITORING OF THE OPTICAL FLUX FROM SCO X-1
}

\author{
Allan Sandage, J. A. Westphal, and Jerome Kristian \\ Mount Wilson and Palomar Observatories, Carnegie Institution of Washington, \\ California Institute of Technology \\ Received June 24, 1968; illustrations revised December 9, 1968
}

\begin{abstract}
Data obtained during five nights of continuous monitoring of the X-ray source Sco X-1 between April and June 1967 are shown in computer-generated point plots.
\end{abstract}

The optical flux of Sco X-1 was continuously monitored on five nights in the spring of 1967 with the 60-, 100-, and 200-inch telescopes. Pulse-counting techniques were used throughout, and the data were recorded directly on punched cards. Integration times of either 2, 4, or $10 \mathrm{sec}$ were employed. The counters were started automatically so that the epoch of each sampling interval advanced at a uniform rate.

Details of the experimental arrangement for each night are given in a previous paper (Westphal, Sandage, and Kristian 1968, hereinafter called Paper I), where some of the data and their implications have been discussed.

We present here computer-generated point plots of the complete data for each night. Plotted as abscissa are the serial numbers of the data samples. The time interval between data points is $5 \mathrm{sec}$, except for the night of May 12, 1967, when observations were made with the 60 -inch using a sampling interval of $15 \mathrm{sec}$.

The ordinate shows the net counts (sky subtracted) obtained during the designated integration time. The secular behavior of the sky was determined from measurements made at intervals throughout each run. A low-order polynomial was fitted to the sky data for each night, and interpolated values were subtracted by computer from each gross data point before plotting. The line in each diagram is a 4-point interpolation curve which is included for easier visualization of the data. It should be noted that the horizontal scales have been chosen so that the time scale is the same on all plots. Markers indicate a 5-min time interval.

Included in each figure is a scale showing the statistics of each data point. No smoothing has been performed on the data presented here. The quoted statistical error refers to each sample point, in contrast to the errors shown in various diagrams of Paper I, which refer to the statistics over the equivalent width of the smoothing filter. It is instructive to compare Figures 1-5 here with Figures 1, 3, 4, and 6 of Paper I.

We will be pleased to send all the numerical data, either as a deck of punched cards or as a listing thereof, to anyone who requests them.

It is a pleasure to thank the personnel of the Astroelectronics Laboratory under the direction of $\mathrm{E}$. W. Dennison, who designed, built, and maintained the data-handling system on the 100- and 200-inch telescopes which formed a major part of our instrumentation.

\section{REFERENCES}

Westphal, J. A., Sandage, A , and Kristian, J. 1968, Ap. J., 154, 139. 

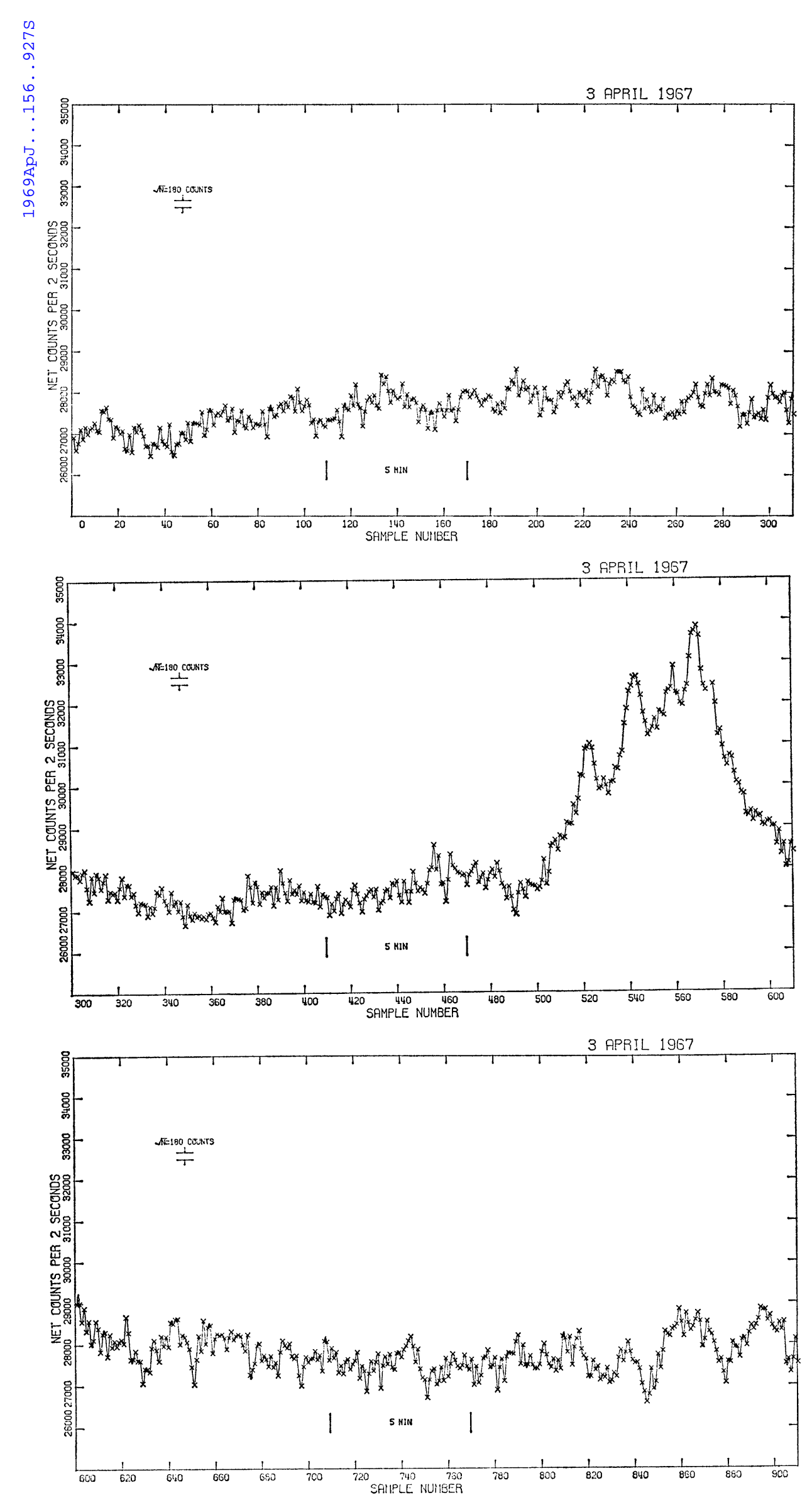

Fig. 1.-Sky-subtracted (net) counts in 2-sec integration times for each 5-sec sample interval obained with the 100-inch reflector on April 3, 1967. 

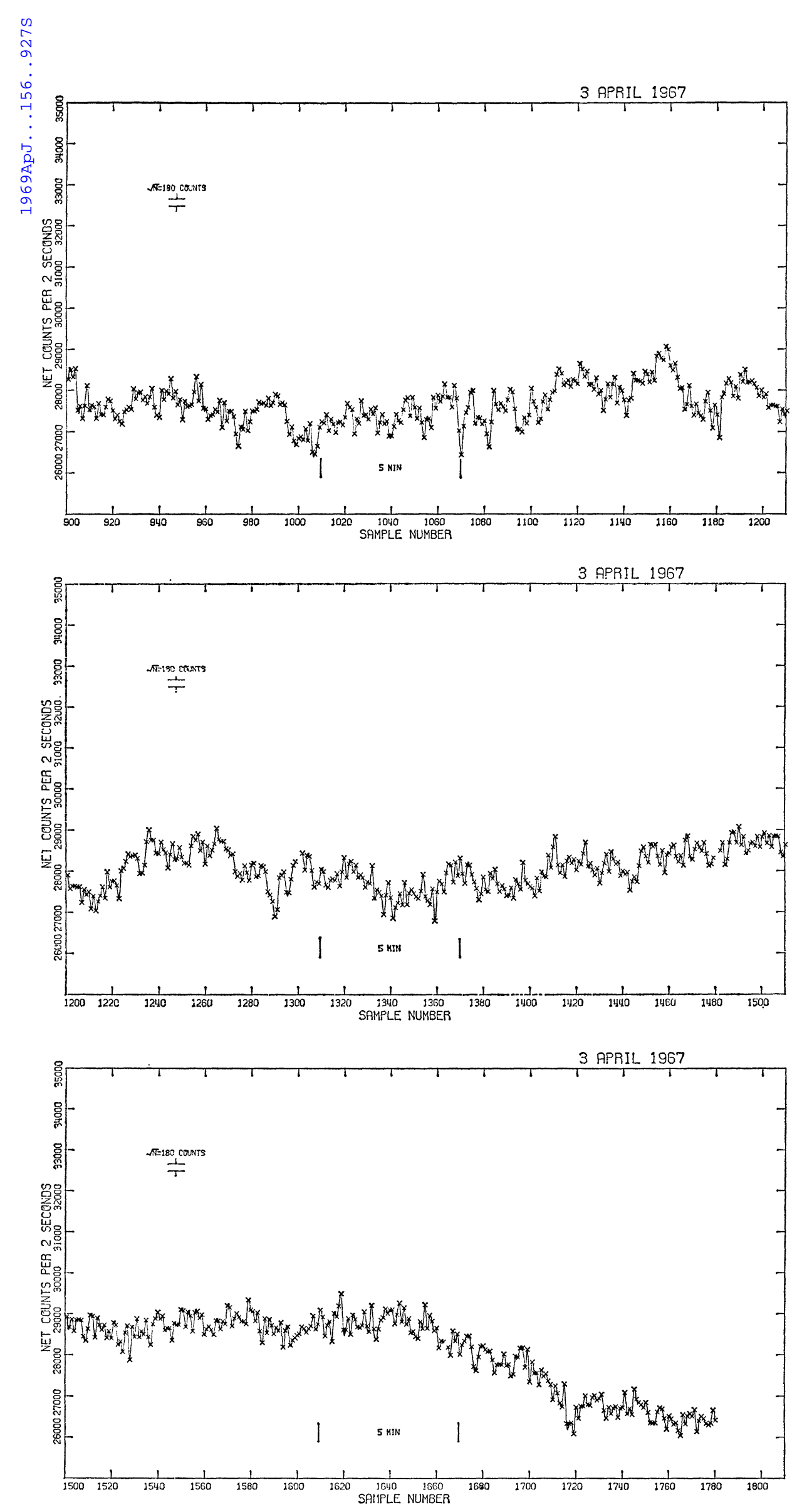

Fig. 1.-Continued 

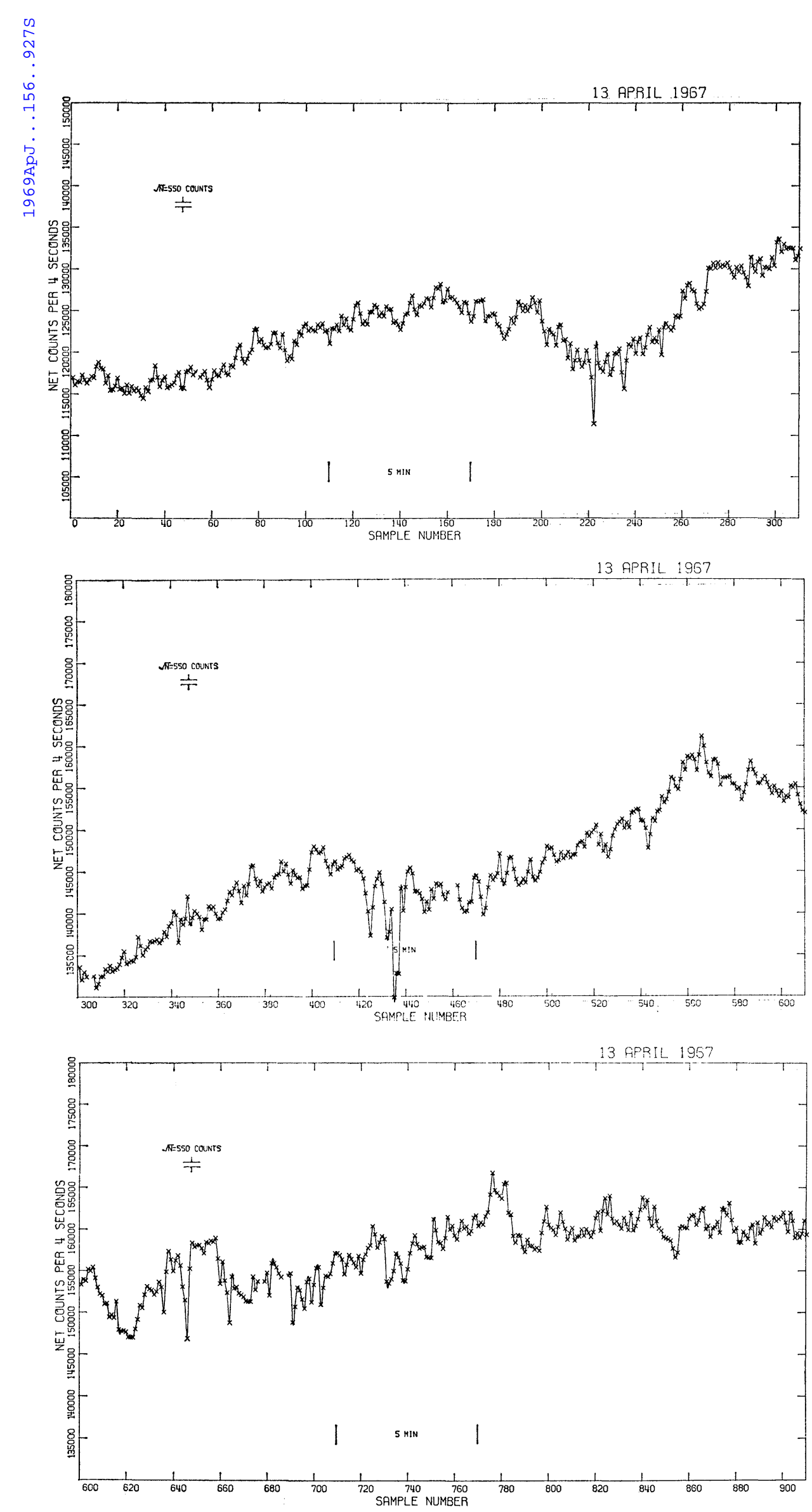

FIG. 2.-Sky-subtracted counts in 4-sec integration times for each 5-sec sample interval obtained with 200-inch reflector on April 13, 1967. 

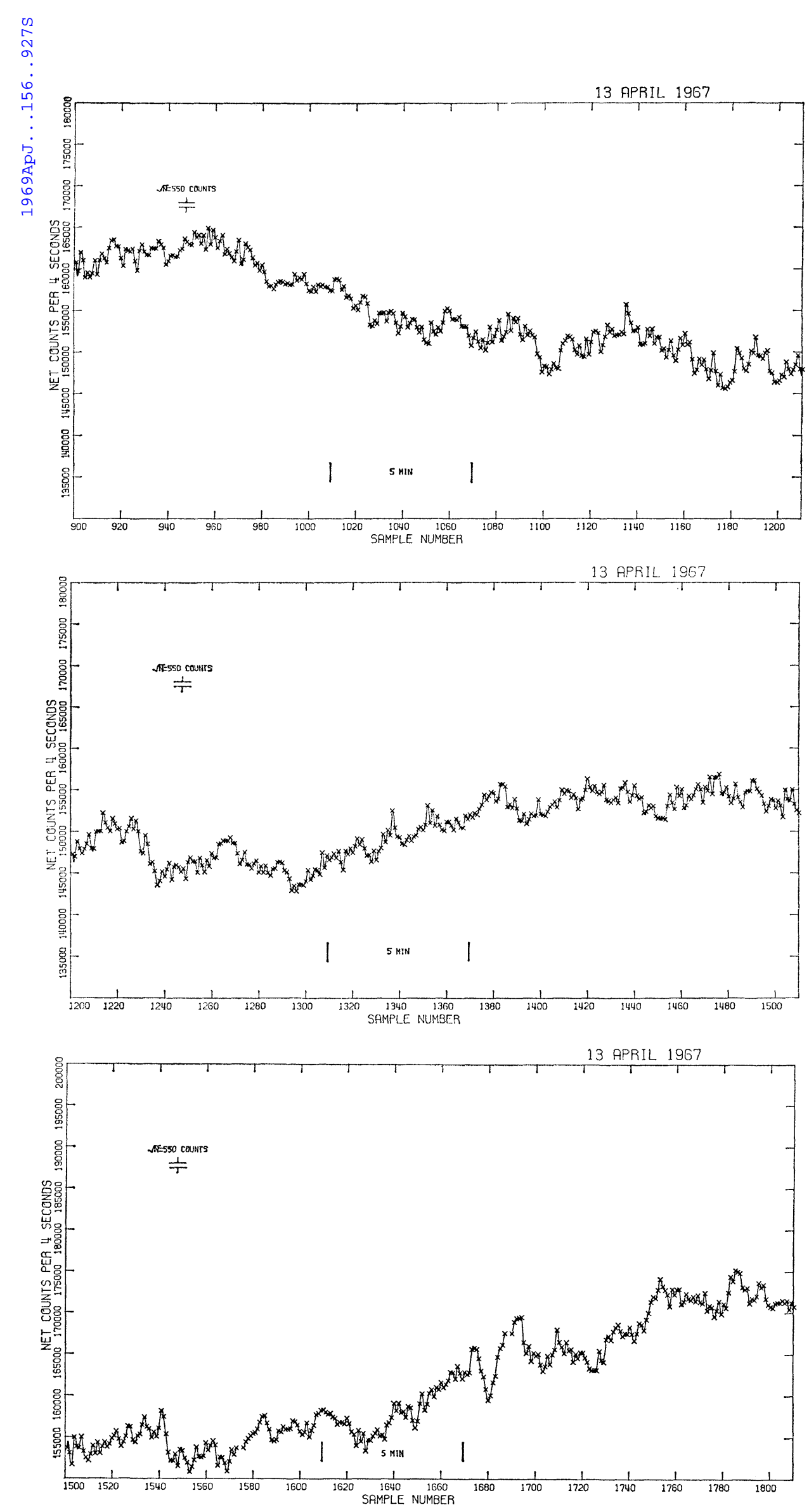

FIG. 2.-Continued 

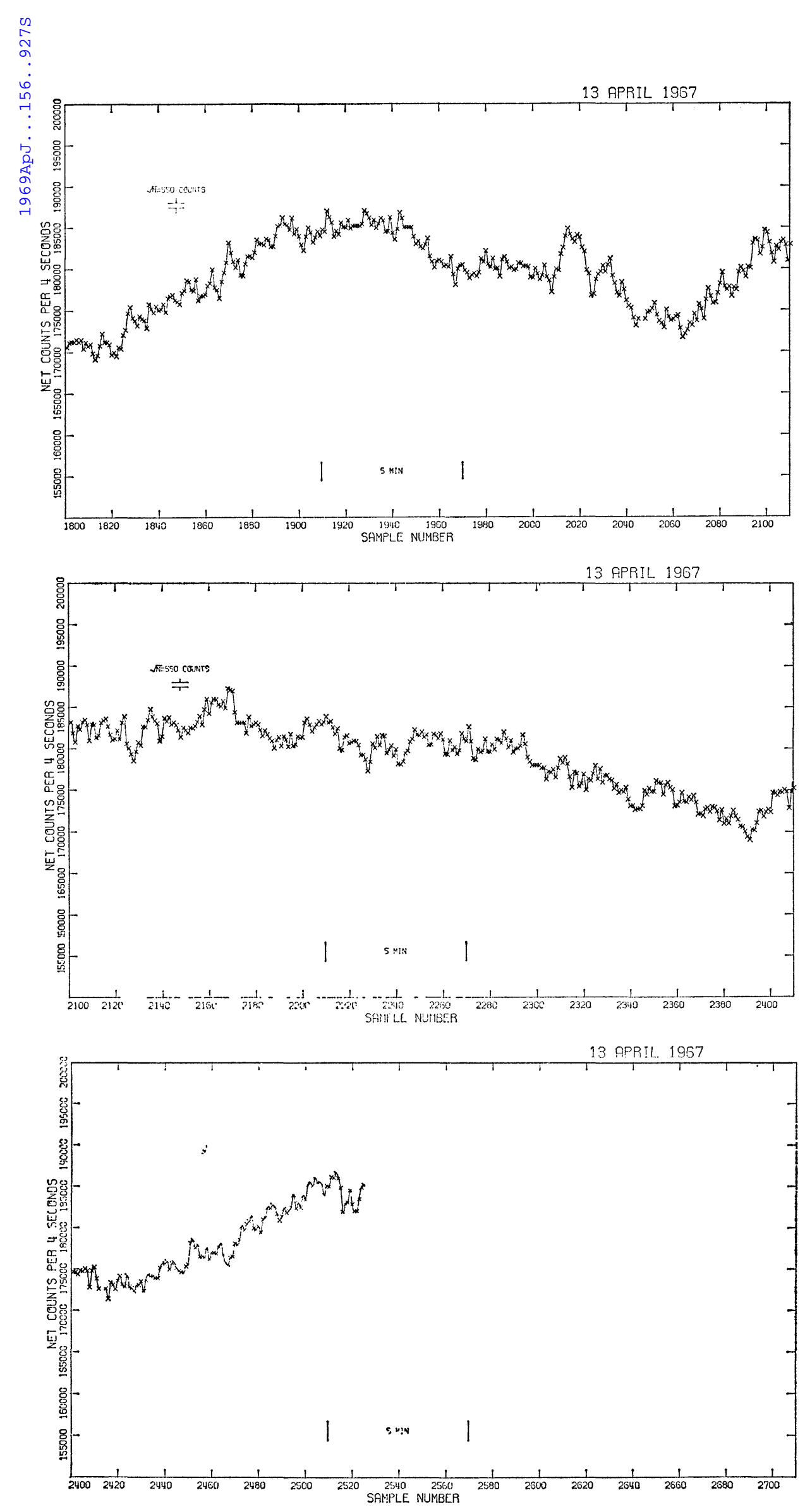

FIG. 2.-Continued 

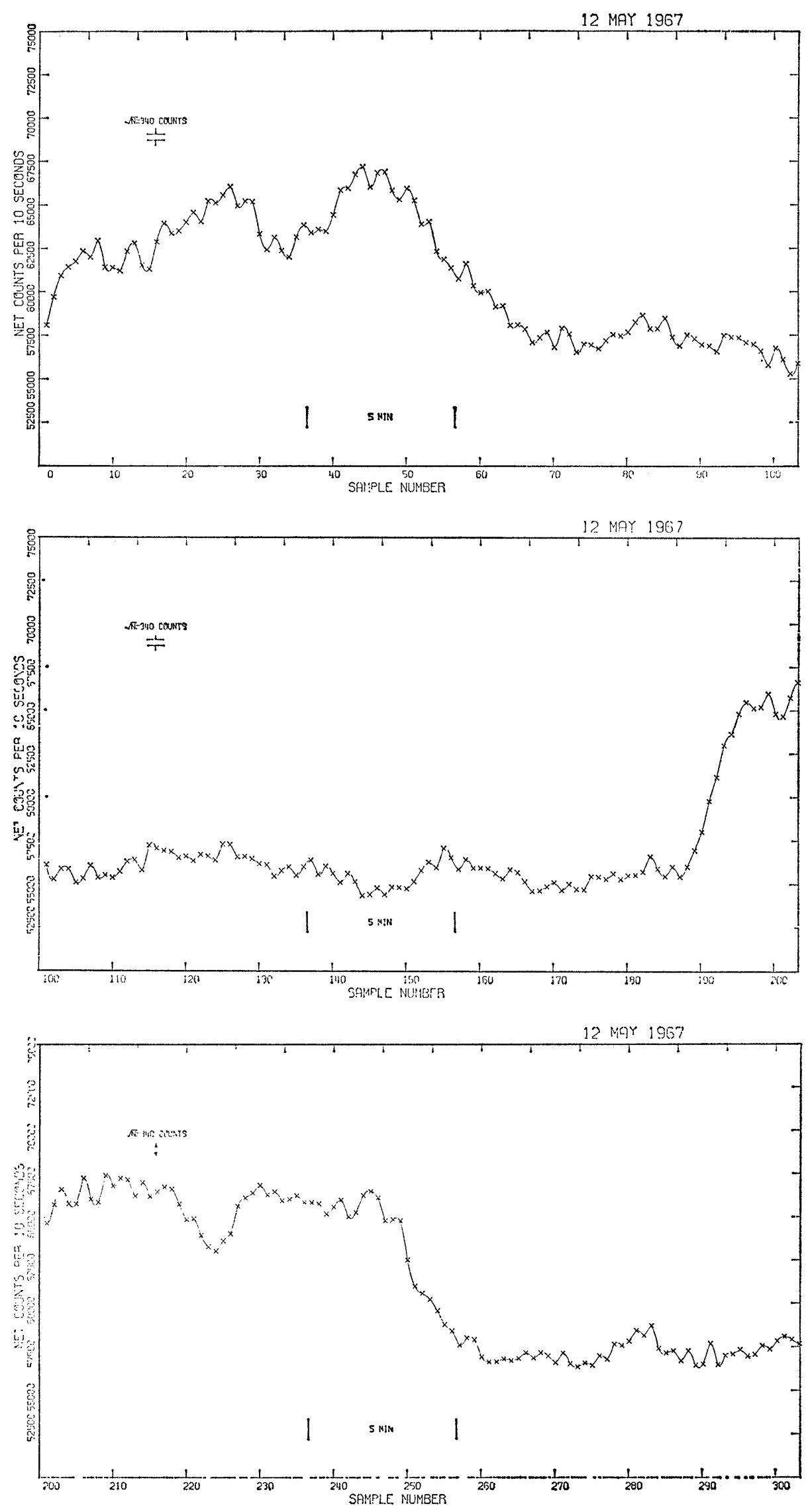

Fig. 3 -Sky-subtracted counts in 10-sec integration times for each 15 -sec sample interval obtained with the 60-inch reflector on May 12, 1967. 

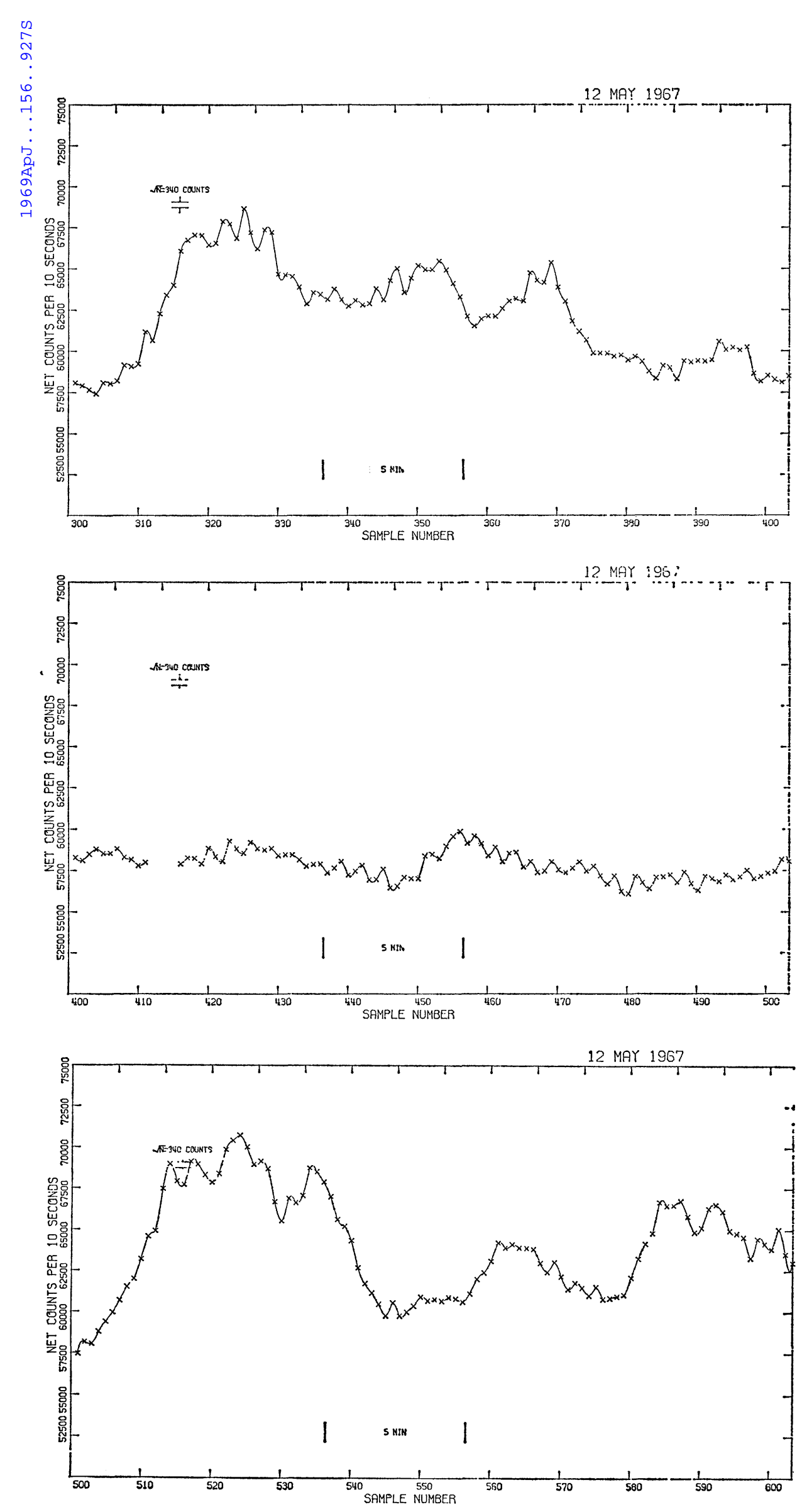

FIg. 3.-Continued 

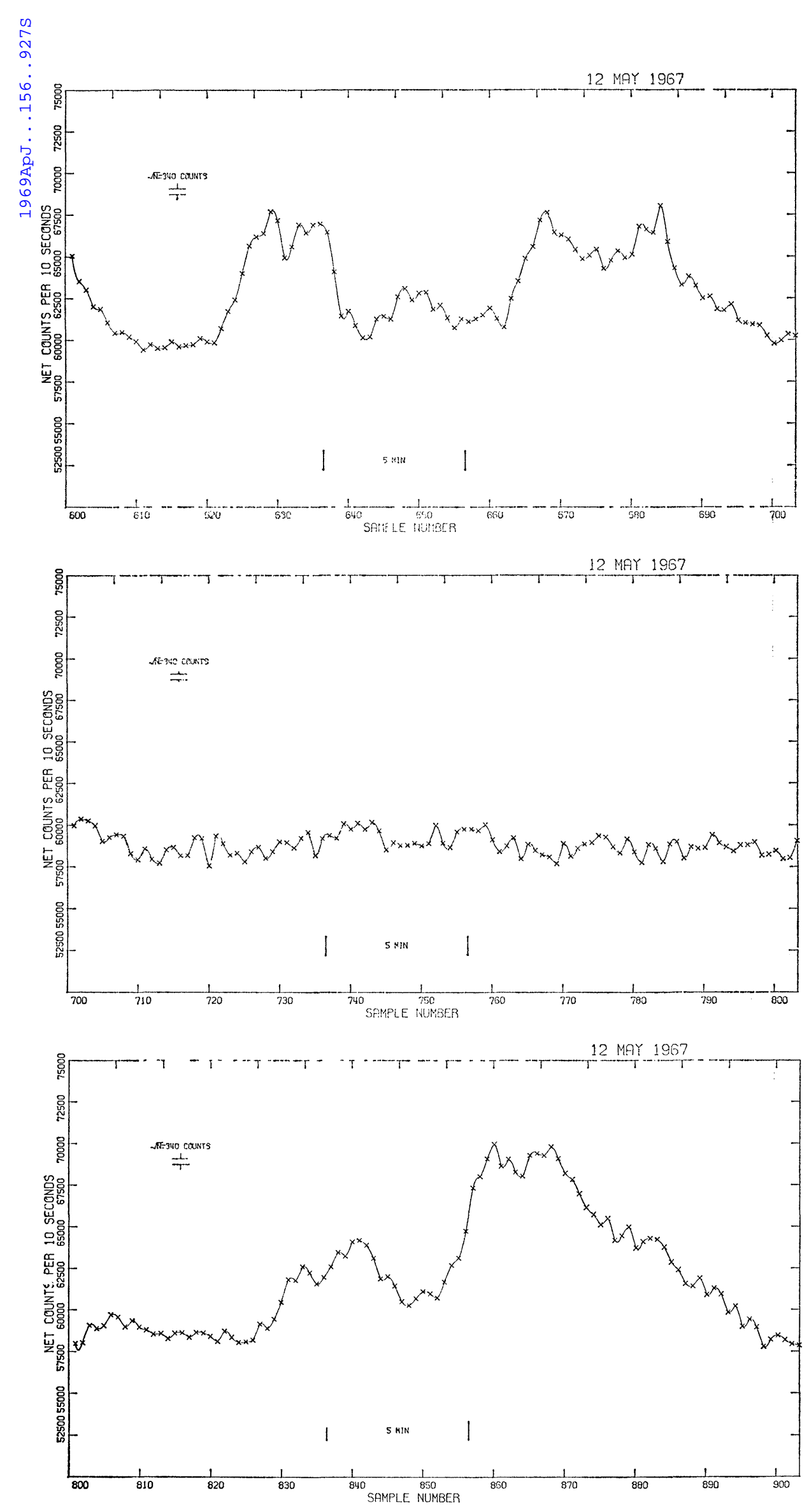

FIG. 3.-Continued 

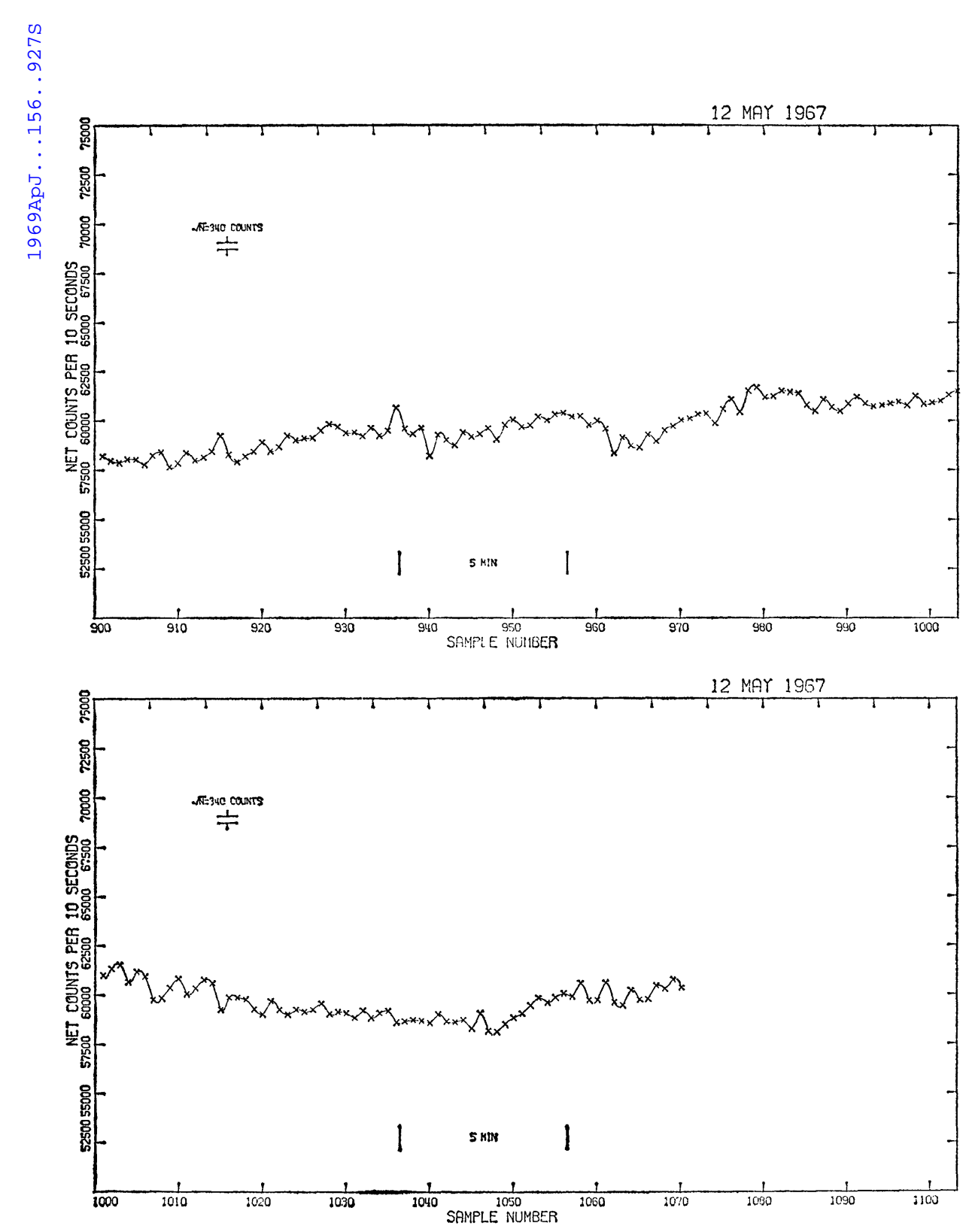

Fig. 3.-Continued

936 

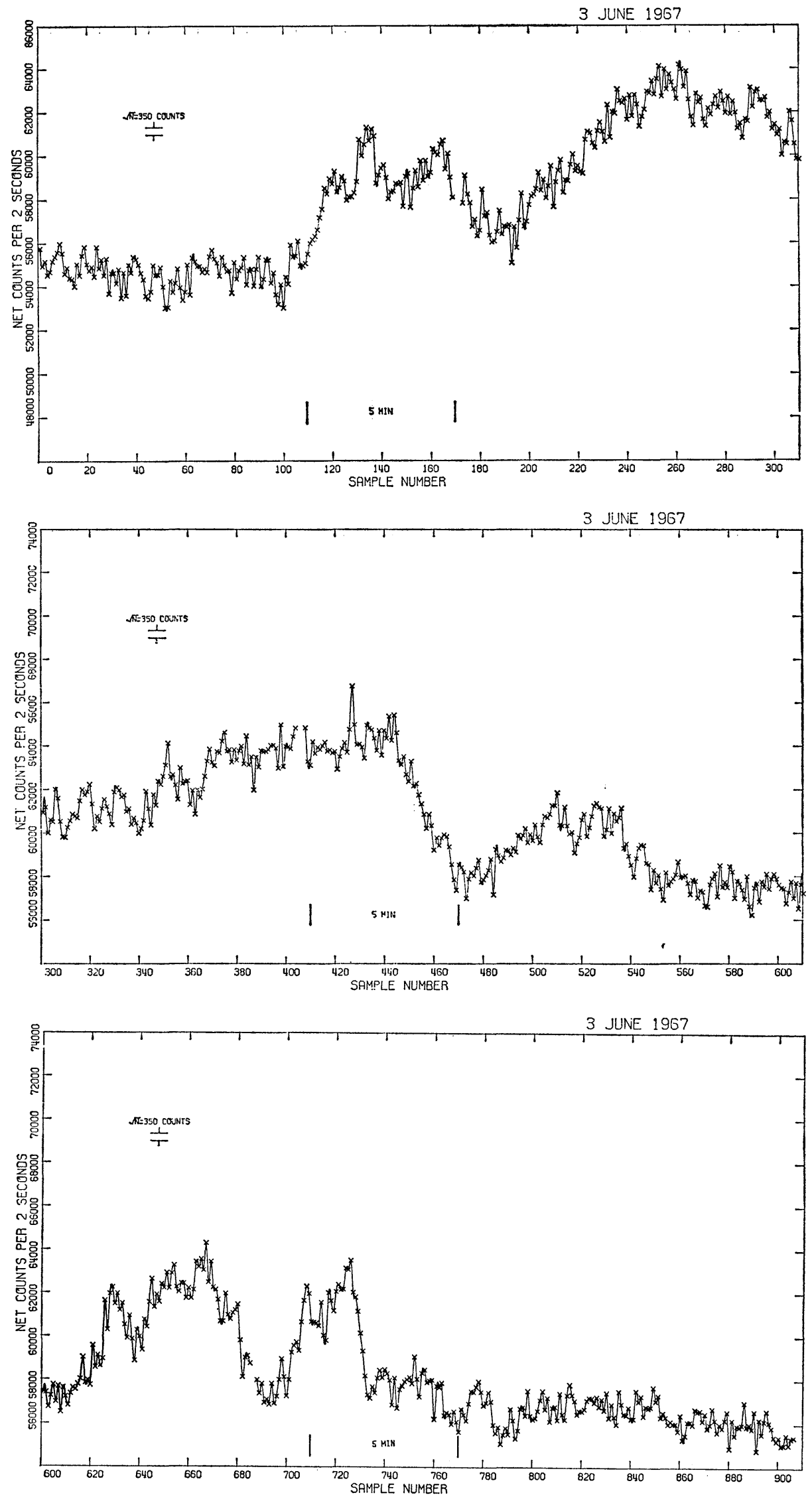

FIG. 4.-Sky-subtracted counts in 2-sec integration times for each 5-sec sample interval obtained with the 100 -inch reflector on June 3,1967 . 

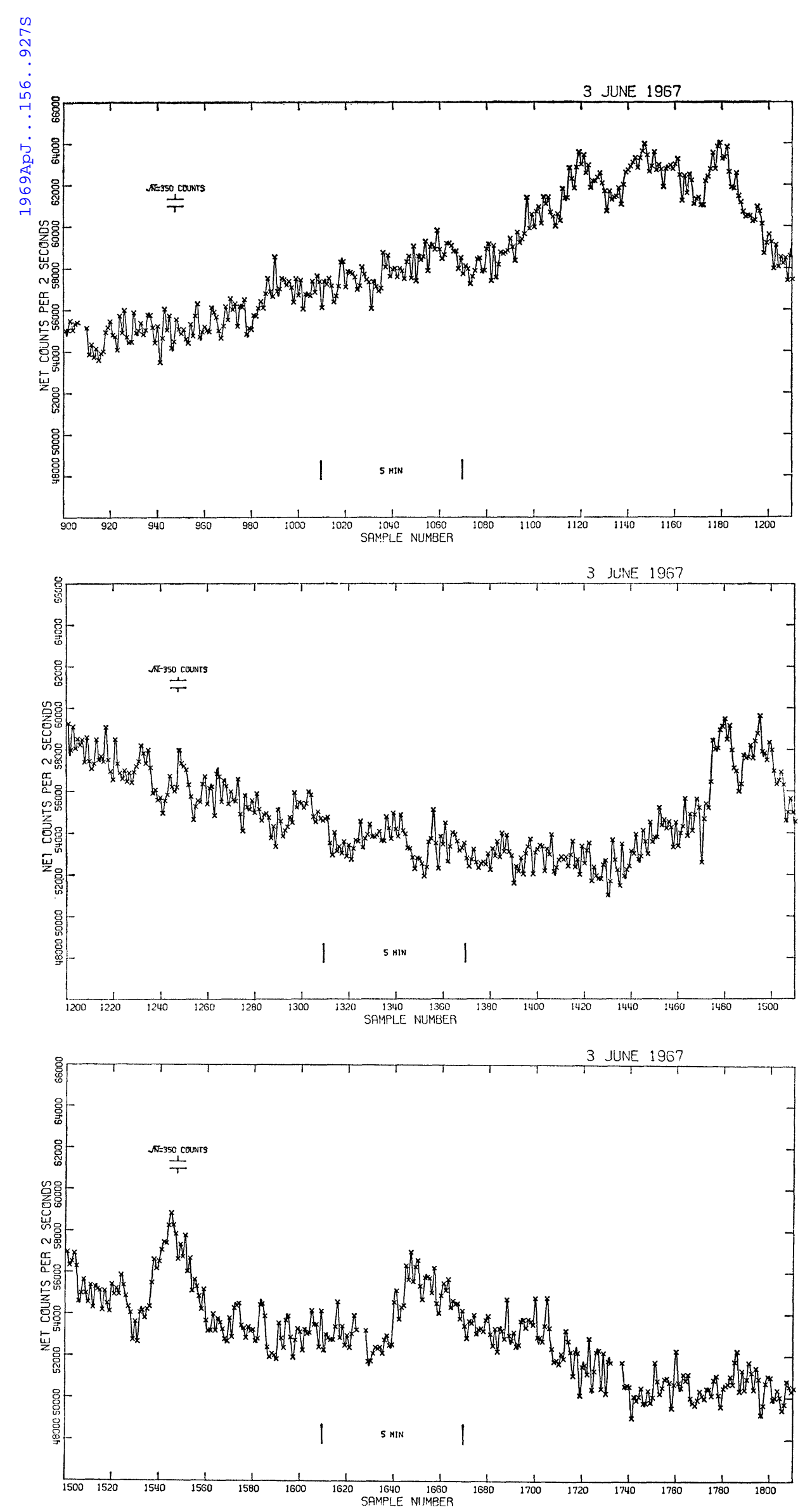

FIG 4-Continued 


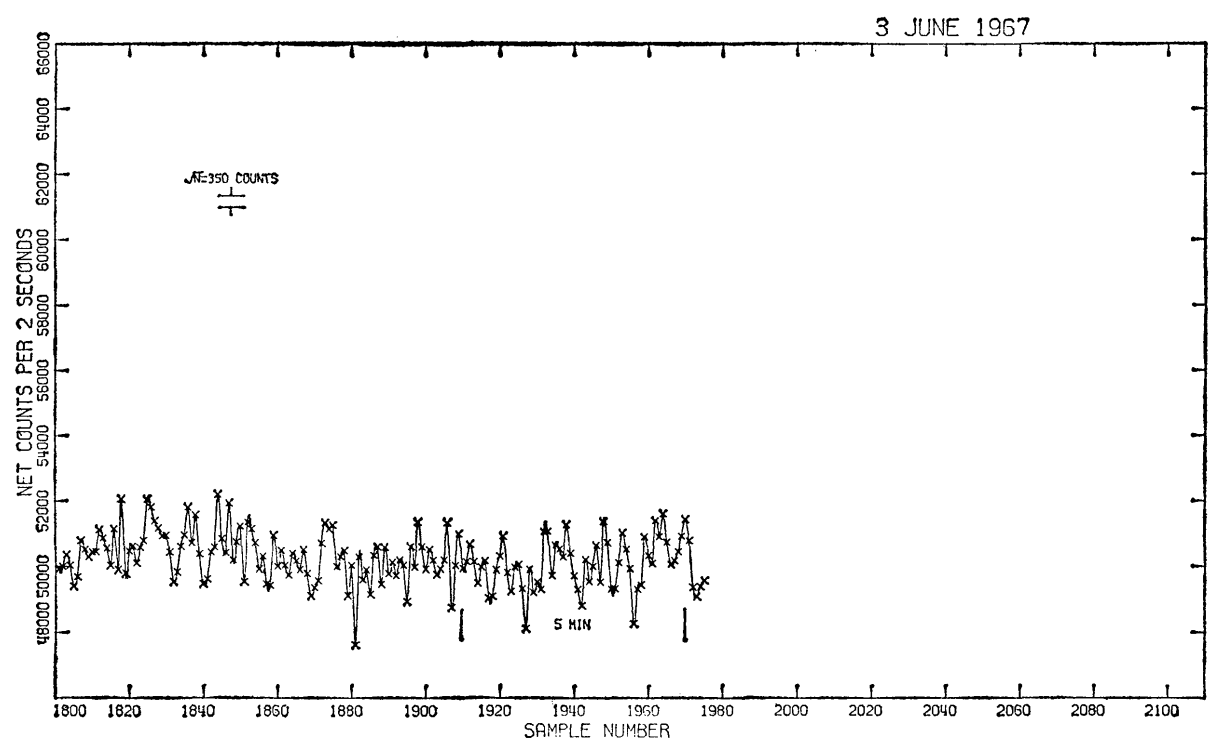

FIG. 4.-Continued 

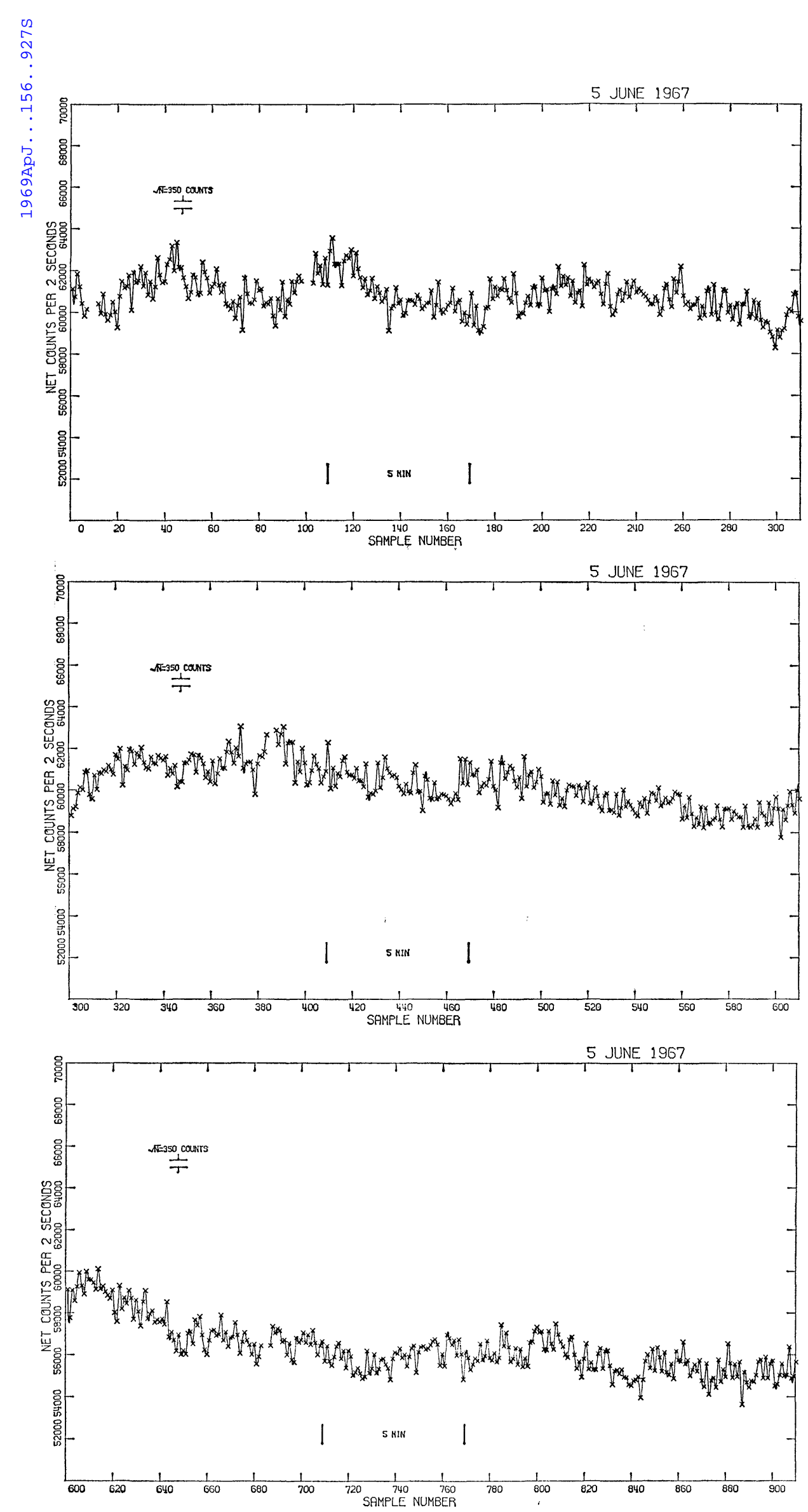

Fig. 5.-Sky-subtracted counts in 2-sec integration times for each 5-sec sample interval obtained with e 100 -inch reflector on June 5,1967 . 

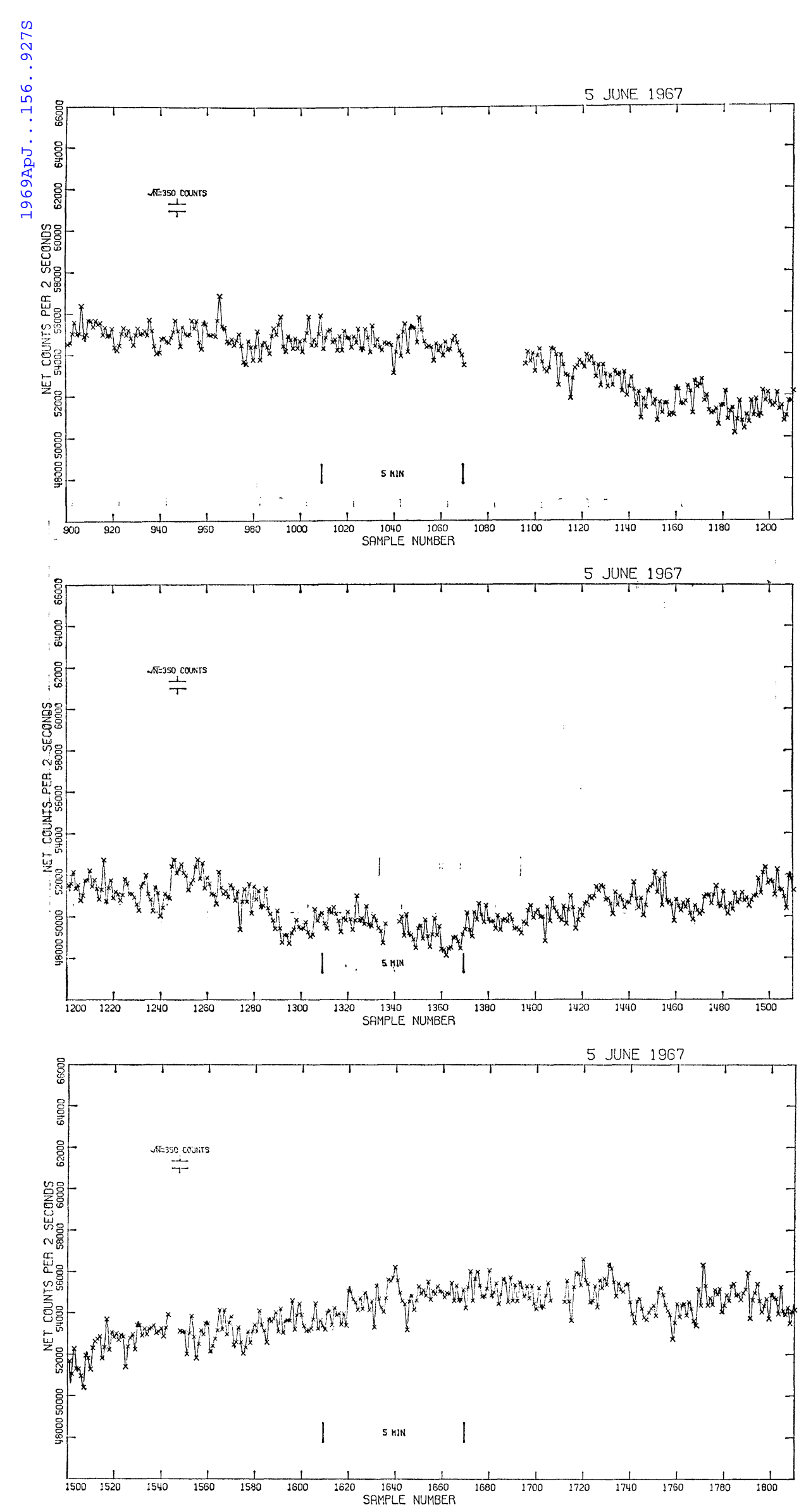

FIG. 5.-Continued 


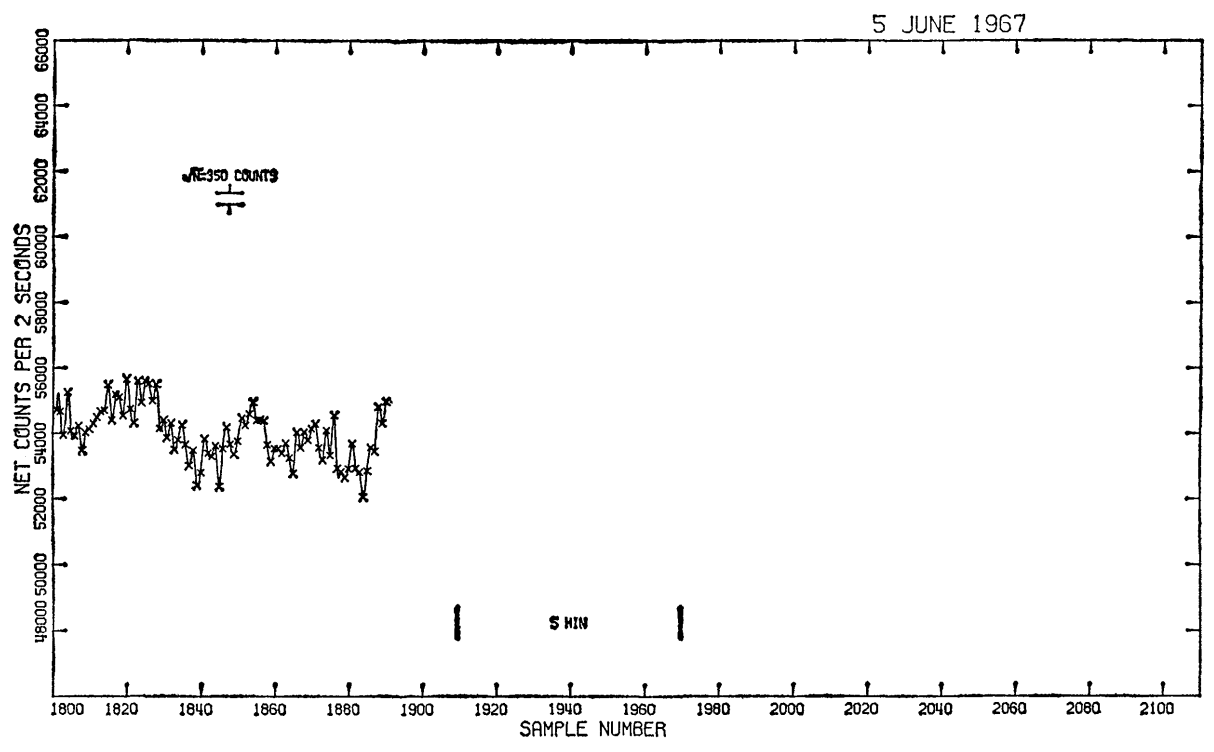

Frg. 5.-Continued 